\title{
BMJ Open An instrument for assessing the quality of informed consent documents for elective procedures: development and testing
}

\author{
Erica S Spatz (D) , ${ }^{1,2}$ Lisa G Suter, ${ }^{2,3}$ Elizabeth George, ${ }^{4}$ Mallory Perez, ${ }^{5}$ \\ Leslie Curry (10 , ${ }^{6,7}$ Vrunda Desai, ${ }^{8}$ Haikun Bao, ${ }^{2}$ Lori L Geary, ${ }^{2}$ Jeph Herrin, ${ }^{1}$ \\ Zhenqiu Lin, ${ }^{2}$ Susannah M Bernheim, ${ }^{2,6,9}$ Harlan M Krumholz (D) ${ }^{1,2}$
}

To cite: Spatz ES, Suter LG, George $\mathrm{E}$, et al. An instrument for assessing the quality of informed consent documents for elective procedures: development and testing. BMJ Open 2020;10:e033297. doi:10.1136/ bmjopen-2019-033297

- Prepublication history and additional material for this paper are available online. To view these files, please visit the journal online (http://dx.doi. org/10.1136/bmjopen-2019033297).

Received 31 July 2019 Revised 19 February 2020 Accepted 07 April 2020

\section{SLinked}

- https://doi.org/10.1136/ bmjopen-2019-033299

Check for updates

(C) Author(s) (or their employer(s)) 2020. Re-use permitted under CC BY-NC. No commercial re-use. See rights and permissions. Published by BMJ.

For numbered affiliations see end of article.

Correspondence to Dr Erica S Spatz; erica.spatz@yale.edu

\section{ABSTRACT}

Objective To develop a nationally applicable tool for assessing the quality of informed consent documents for elective procedures.

Design Mixed qualitative-quantitative approach.

Setting Convened seven meetings with stakeholders to obtain input and feedback on the tool.

Participants Team of physician investigators, measure development experts, and a working group of nine patients and patient advocates (caregivers, advocates for vulnerable populations and patient safety experts) from different regions of the country.

Interventions With stakeholder input, we identified elements of high-quality informed consent documents, aggregated into three domains: content, presentation and timing. Based on this comprehensive taxonomy of key elements, we convened the working group to offer input on the development of an abstraction tool to assess the quality of informed consent documents in three phases: (1) selecting the highest-priority elements to be operationalised as items in the tool; (2) iteratively refining and testing the tool using a sample of qualifying informed consent documents from eight hospitals; and (3) developing a scoring approach for the tool. Finally, we tested the reliability of the tool in a subsample of 250 informed consent documents from 25 additional hospitals.

Outcomes Abstraction tool to evaluate the quality of informed consent documents.

Results We identified 53 elements of informed consent quality; of these, 15 were selected as highest priority for inclusion in the abstraction tool and 8 were feasible to measure. After seven cycles of iterative development and testing of survey items, and development and refinement of a training manual, two trained raters achieved high item-level agreement, ranging from $92 \%$ to $100 \%$.

Conclusions We identified key quality elements of an informed consent document and operationalised the highest-priority elements to define a minimum standard for informed consent documents. This tool is a starting point that can enable hospitals and other providers to evaluate and improve the quality of informed consent.
Strengths and limitations of this study

- The abstraction tool was developed with input from patients and patient advocates to establish a minimum standard for informed consent documents.

- The tool needed to be applicable to a broad range of procedures and may not capture high-priority quality elements that are specific to a procedure.

- A training manual was developed to support the reliable assessment of the eight items in the abstraction tool.

- The abstraction tool establishes only a minimum standard for informed consent documents, not a definitive benchmark of achievement.

- Evaluation of the informed consent document alone may not reflect the total quality of the informed consent process, although it is a key component.

\section{INTRODUCTION}

Informed consent, an ethical obligation and legal mandate intended to uphold patient autonomy, is a standard part of clinical practice, performed prior to most procedures and therapies with material risks. In the USA, approximately 19 million hospital-based procedures requiring informed consent are performed each year. ${ }^{1}$ This integral part of clinical care offers an opportunity for clinicians to help patients learn about the rationale for the proposed procedure, how it is performed, its potential risks and benefits, and reasonable alternatives. A high-quality informed consent process additionally helps the patient consider what is important to them and prepares the patient to make a decision regarding his or her care. ${ }^{2-5}$ However, studies indicate that informed consent is often conducted in a cursory manner, minutes before a procedure when patients may feel vulnerable and less able to process complex information. ${ }^{6-10}$ In addition, informed 
consent documents used to support these discussions are frequently generic, lacking information that is specific to the procedure or the patient. Typically, consent forms are used to affirm consent (and thereby minimise risks for litigation) rather than provide meaningful information for patients. ${ }^{11}$ These flaws undermine patient autonomy, the patient-clinician relationship and the aim of providing high-quality care that aligns with patients' preferences, values and goals.

As part of a contract to develop quality measures for the Centers for Medicare and Medicaid Services (CMS), we at the Yale-New Haven Health Center for Outcomes Research and Evaluation (CORE) conducted the foundational work for measuring the quality of informed consent documents used by clinicians in diverse health systems, with the goal of bolstering patient-centred decision making. Conceptually, we sought to identify aspects of informed consent quality that are feasible to measure on a national scale across diverse procedure types, and that, if improved, could give patients a more reliable, patient-centred informed consent experience. ${ }^{12-14}$

In order to assess informed consent quality, we focused on the informed consent document and began by creating an abstraction tool to capture key aspects of document quality. While much of what represents quality in the informed consent process is difficult to assess without direct observation, ${ }^{15}$ some properties of the informed consent process are reflected in the informed consent document, including timing and information specific to the procedure. Additionally, if the document does not reflect key information about the procedure, this raises concerns regarding quality, as one cannot assume that the patient actually received sufficiently comprehensive, detailed and appropriate information. ${ }^{16}$ Ideally, the information within the informed consent document should support the transfer of comprehensible written information to patients and families, making the document a necessary, although not sufficient, step in supporting patient autonomy. While informed consent documents cannot alone reflect the quality of the informed consent process, a patient-centred document can uphold a more complete concept of informed consent, namely transparency of information, recognition of uncertainty, elicitation of patient preferences and goals, and a more inclusive process that supports patients and their care networks in being more participatory in the decision-making process.

To develop a tool to evaluate informed consent quality, we first constructed a taxonomy of key elements of highquality informed consent documents with the input of patients, patient advocates and a technical expert panel, using a consensus-based set of standards. Next, we used this taxonomy to build an instrument for assessing the quality of informed consent documents. As described in this manuscript, the instrument was iteratively developed and tested to achieve high reliability. In a companion manuscript entitled, 'Quality of informed consent documents among U.S. hospitals: a cross-sectional study', ${ }^{17}$ we describe the use of the tool in a cross-sectional study evaluating the quality of informed consent documents tied to elective procedures performed in 25 hospitals. Ultimately, the instrument is designed to be used by individual clinicians and provider groups, hospitals and health systems to assess the quality of informed consent documents used in real-world clinical settings.

\section{METHODS}

\section{Overview}

Although the CMS and the Joint Commission provide guidance for the informed consent process ${ }^{18-20}$ precise standards for assessing the quality of informed consent documents are lacking. Therefore, we first developed a taxonomy of elements of high-quality informed consent documents. Using that taxonomy, we developed an abstraction tool using informed consent documents from a development sample of eight hospitals, iteratively testing and refining each item. We then tested the reliability of the final abstraction tool in a testing sample of informed consent documents from 25 collaborating hospitals.

Collaborating hospitals were recruited through two partnering organisations, the Hospital Services Advisory Group and Premier. These organisations facilitated the collection of informed consent documents from the medical charts of patients who had underwent procedures at the collaborating hospitals. Since the names of patients and clinicians were redacted from the consent forms prior to review, we did not obtain informed consent from patients or clinicians.

Only informed consent documents for elective procedures were used in the development and testing samples. To identify the elective procedures performed at each of the collaborating hospitals, we used Medicare Fee-forService claims data. First, we limited the procedures to those in which informed consent is standard practice. Next, we used an algorithm to determine whether the procedures were conducted on an elective basis (the Planned Readmissions Algorithm).$^{21}$ In this algorithm, procedures are identified as 'always' or 'potentially' planned and occurring during admissions for non-acute conditions. We then grouped these procedures into 10 surgical divisions based on surgical service line. Finally, to generate the list of procedures for each hospital to collect and send for review, we used a purposeful sampling approach, selecting procedures that were representative of a hospital's procedure mix.

\section{Patient and public involvement}

We convened a working group of nine patients and patient advocates (caregivers, advocates for vulnerable populations, legal representatives and patient safety experts) to inform the development of the taxonomy and the abstraction tool. Importantly, the purpose of the working group was to engender discussion about informed consent, allow for the introduction of new ideas and deconstruction of concepts, and to get their input on the iterative development of a tool that could be used to assess informed 
consent document quality. The purpose was not to reach group consensus on specific concepts or on the tool itself. Specifically, when there were disagreements among the group members, or between the group members and the researchers, we worked towards a shared understanding, recognition of the constraints of this measure and consideration of other approaches (outside of this work) that may support the goal.

Five members were nominated by the National Partnership for Women \& Families (a non-profit organisation partnered with CORE to provide input on measure development from the patient's perspective). Two were recruited given their reputation as nationally recognised patient advocates. Additionally, two local health leaders were recruited to represent the concerns of diverse populations: one, a director of a non-profit organisation that supports the rights of underserved and minority populations, and the other a legal expert in healthcare law, with former executive positions in several large healthcare systems. Members were from Connecticut, Colorado, Minnesota, Massachusetts and Maryland, and worked with our team of clinicians and quality measurement experts during the course of seven meetings (described in the following section), providing critical feedback on and revisions to the taxonomy and abstraction tool.

\section{Developing the taxonomy}

To develop the taxonomy, we sought to identify elements of the informed consent process that were meaningful and feasible to measure. We first conducted an environmental scan and literature review of informed consent and its ethical and legal requirements in a clinical setting, along with the evidence supporting whether improved informed consent documents can increase decisional quality. Second, we conducted an exploratory study (previously published ${ }^{10}$ of a convenience sample of informed consent documents for three cardiovascular procedures. We also reviewed state and national legal standards for informed consent documents, statements from regulatory agencies (such as CMS and the Joint Commission), and professional societies $(\mathrm{n}=13$; online supplementary file 1).
From this extensive review, we identified three domains of quality for informed consent documents: content, presentation and timing (figure 1). After each domain was deconstructed into several 'dimensions' and further into 'elements', we developed a draft taxonomy. We then conducted seven 90 min meetings with the working group members to elicit feedback on the taxonomy and develop the abstraction tool. In the first meeting, we asked group members to share their backgrounds, experiences and perspectives relevant to informed consent. During the next three meetings, the group discussed each respective domain of the draft taxonomy (content, presentation, timing) and its associated dimensions and elements. During the fifth meeting, we presented the revised taxonomy, which incorporated the working group's prior input as well as feasibility assessments from a range of clinicians. We also asked them to complete a survey identifying the taxonomy dimensions they considered to be of highest priority. After developing the abstraction tool (described in the following sections), we conducted two final meetings with the working group to confirm their high-priority selections.

\section{Developing the abstraction tool}

Using the taxonomy, we developed an abstraction tool for use in a measure to evaluate informed consent document quality. This tool took the form of a checklist to evaluate a set of standard criteria that each document should reasonably meet.

Phase 1: selection of elements from the taxonomy for evaluation by the abstraction tool

We identified five principles for selecting elements from the taxonomy (table 1). Using these principles, we identified and operationalised high-priority elements for inclusion in the first draft of the tool.

Phase 2: iterative testing of the abstraction tool

Elements selected for inclusion in the abstraction tool were defined as 'items', and criteria were developed to guide assessment of each item, captured in the Instructions Manual (online supplementary file 2). The tool and

- Content: information in the document for the patient to read, such as explanations of the procedure and its risks, benefits, alternative treatment options, and expected results.

- Presentation: how the document displays the information, including legibility, readability, use of lay language, and clarity of non-text information (e.g., figures).

- Timing: when the informed consent document is presented to and discussed with the patient, usually indicated by the patient's or proxy's signature.

Figure 1 Taxonomy domains describing informed consent document quality. 


\begin{tabular}{|c|c|}
\hline Principle & Definition \\
\hline Importance to patients & $\begin{array}{l}\text { Element should reflect what most patients, families and caregivers perceive as important to } \\
\text { them. }\end{array}$ \\
\hline Evidence-based & $\begin{array}{l}\text { Element is supported by consensus-based guidelines, documented best practices, } \\
\text { standards or benchmarks - from regulatory bodies, professional societies or national } \\
\text { institutes (online supplementary file 1). }\end{array}$ \\
\hline Relevance to cohort & $\begin{array}{l}\text { Element is relevant to informed consent documents for all elective procedures, regardless of } \\
\text { level of invasiveness or surgical specialty. } \\
\text { Element is pertinent to a diversity of patients who have varying healthcare preferences and } \\
\text { needs. }\end{array}$ \\
\hline Ease of collection & $\begin{array}{l}\text { Element can be assessed in a manner in which data collection does not place an undue } \\
\text { burden on patients and hospitals (eg, related to medical chart abstraction and data transfer). }\end{array}$ \\
\hline Reliability of measurement & $\begin{array}{l}\text { Element can be defined and measured in a consistent way such that clear instruction and } \\
\text { training of raters yield high inter-rater reliability. }\end{array}$ \\
\hline
\end{tabular}

associated instruction manual were iteratively tested in multiple cycles. In each cycle, 5-12 raters used the tool to rate 10 informed consent documents, obtained from the eight pilot hospitals, and qualitatively selected for their diversity in procedure type and detail. Between cycles, we reviewed the language of each item, refined our approach for training raters and clarified our abstraction instructions (ensuring standardised application across all raters).

\section{Phase 3: initial development of the scoring approach}

To develop a point system for scoring, including how many points to assign each item on the abstraction tool, we considered the following: the level of evidence supporting each item (weighting items with published standards and guidelines more heavily); item reliability (weighting items with greater reliability more heavily); and importance to patients (weighting items that are most important to patients more heavily).

We then proposed a scoring system and solicited feedback on it from the patient working group. We also sought feedback from an independent technical expert panel, convened to provide feedback on the informed consent measure for which the tool would be used in; this panel comprised surgeons and other clinicians, lawyers, and experts in bioethics, health literacy and cultural competency.

\section{Phase 4: reliability testing}

To assess the reliability of the tool, we trained as raters two medical-record coders for a large hospital system who had no prior experience in rating informed consent documents. For the training, we used the final instruction manual, which included a 1-hour video, and provided feedback to the raters on 10 practice consent documents.

The final reliability testing was conducted in a testing sample of 25 hospitals.

From these hospitals, 10 informed consent documents $(n=250)$ were randomly selected for review. We trained two raters using a standardised 1-hour training module and then had them review, independently, the sample of documents. We assessed inter-rater agreement for each item using per cent agreement and Cohen's kappa statistic for item reliability. The iterative versions of the abstraction tool can be made available on request. The informed consent documents used to develop and test the abstraction tool cannot be shared given the confidential patient and provider information, and data use agreements with CMS and partnering hospitals.

\section{RESULTS}

Based on the findings of the literature review and environmental scan, informed consent standards, the exploratory study of medical records, and the working group's input, we developed the taxonomy as an expanded, comprehensive list of 53 components of informed consent documents that reflect the decisional needs of patients (table 2).

\section{Abstraction tool}

We identified a subset of elements from the taxonomy that represent the minimum, patient-defined standards for informed consent document quality, are feasible to measure, and are consistent with recommendations from government agencies and professional societies. Using these principles, we initially selected 15 taxonomy elements for inclusion in the first draft of the abstraction tool as items: document in preferred language or use of an interpreter; purpose of procedure; plain language; anticipated mode of anaesthesia; procedure-specific risks; quantitative probability of risks; qualitative probability of risks; procedure-specific benefits; quantitative probability of benefits; qualitative probability of benefits; alternatives stated; postoperative expectations for recovery; inclusion of special clauses (eg, use of photography, presence of students/trainees, use of tissue samples and so on); legibility; and timing. These items were also prioritised by the working group as meaningful components of informed consent document quality from the patient's perspective. 
Table 2 Taxonomy of informed consent quality elements

\begin{tabular}{|c|c|c|}
\hline Domain ( $n=3)$ & Dimension $(n=20)$ & Element $(n=53)$ \\
\hline \multirow[t]{24}{*}{ Content } & \multirow[t]{3}{*}{ Description of procedure } & 1. Rationale for the procedure. \\
\hline & & 2. Level of invasiveness. \\
\hline & & 3. Steps of the procedure. \\
\hline & \multirow{4}{*}{$\begin{array}{l}\text { Postoperative expectations for } \\
\text { procedure }\end{array}$} & 4. Estimated recovery time. \\
\hline & & 5. Estimated time before the patient can return to work or normal activity. \\
\hline & & 6. Whether there is need for a family caregiver following the procedure. \\
\hline & & 7. Description of how the procedure will influence future care (eg, follow-up visits). \\
\hline & \multirow[t]{4}{*}{ Goals (benefits) of procedure } & 8. What the patient hopes to get out of the procedure, tied to the patient's care plan. \\
\hline & & 9. What the procedure will not achieve. \\
\hline & & 10. Procedure-specific benefits. \\
\hline & & 11. General quantitative probabilities of benefits occurring. \\
\hline & \multirow[t]{3}{*}{ Disclosure of risks/side effects } & 12. Procedure-specific risks. \\
\hline & & 13. General quantitative probabilities of risks occurring. \\
\hline & & 14. Distinction between minor risks (side effects) and major risks. \\
\hline & \multirow[t]{2}{*}{ Alternatives to procedure } & $\begin{array}{l}\text { 15. Potential alternative treatment options (eg, medication/physical therapy, alternative procedure, watch } \\
\text { and wait, no treatment). }\end{array}$ \\
\hline & & 16. Anticipated outcomes associated with potential alternative treatment options. \\
\hline & \multirow{4}{*}{$\begin{array}{l}\text { Hospital-specific and/or physician- } \\
\text { specific performance }\end{array}$} & 17. Procedure volume (ie, the number of procedures performed) by physician/at hospital. \\
\hline & & 18. Procedure success rate of physician/hospital. \\
\hline & & 19. Procedure complication rate of physician/hospital, including postoperative complications (eg, infection). \\
\hline & & $\begin{array}{l}\text { 20. Cost of the procedure (eg, may refer to hospital's base cost, noting that this is not the cost to the } \\
\text { patient). }\end{array}$ \\
\hline & \multirow[t]{4}{*}{ Patient safety check } & 21. Review of medications taken by the patient, including over-the-counter medications. \\
\hline & & 22. List of allergies. \\
\hline & & 23. Note of prior reactions to anaesthesia (yes/no). \\
\hline & & $\begin{array}{l}\text { 24. Agreement between operative report and consent document, with caveat for unexpected findings/ } \\
\text { complications during procedure. }\end{array}$ \\
\hline Content & Additional resources & $\begin{array}{l}\text { 25. Invitation for others, such as family caregivers, spouse and child, to be included in informed consent } \\
\text { discussion. }\end{array}$ \\
\hline
\end{tabular}

26. Invitation for additional medical consultation (eg, discussion with primary care provider or a second opinion).

27. Reference to decision aids, patient education brochures, videos or links to relevant web pages.

28. Phone numbers for support (eg, hospital's patient relations, nurse/physician hotline or Department of Public Health).

29. Referral to patient peer groups.

Opt-out or strikeout instructions 30. Presence and role of students and trainees.

31. Permission to take pictures or video for educational, advertising and/or other public purposes.

32. For-profit use of tissue/specimen.

33. Blood transfusion with description of risks if patient opts out.

Type of anaesthesia

34. Description of anticipated type of anaesthesia:

a. Conscious sedation.

b. Local anaesthesia.

c. Regional anaesthesia (eg, spinal, epidural).

d. General anaesthesia.

e. Local nerve block.

Description of risks of anaesthesia 35. General risks of anticipated type of sedation/pain control.

36. Patient-specific risks of anticipated type of sedation/pain control.

Postoperative expectations for anaesthesia

37. Recovery time from anaesthesia (eg, duration of unconsciousness, somnolence and cognitive effects)

38. Disclaimer that recovery time may vary by patient.

39. Instructions on immediate follow-up (eg, driving, operating machinery).

Format

40. Identification of the method of distribution: patient portal, website link, electronic copy received via email, paper copy distributed at office, paper copy mailed to patient.

41. Alignment with the patient's preferred method for reviewing the document (may be more than one format). 


\begin{tabular}{|c|c|c|}
\hline Domain $(n=3)$ & Dimension $(n=20)$ & Element $(n=53)$ \\
\hline Content & Accessibility & $\begin{array}{l}\text { 42. Notation that the patient was offered: } \\
\text { a. Braille or audio version of the document. } \\
\text { b. Large-font document. } \\
\text { c. Document in patient's preferred language. } \\
\text { d. Language interpretation/translation services. }\end{array}$ \\
\hline \multirow[t]{8}{*}{ Presentation } & Legibility & 43. All information is typed. \\
\hline & & 44. Minimum font size. \\
\hline & & $\begin{array}{l}\text { 45. Minimum resolution (ie, visual clarity of language, avoiding blurred or overexposed printed/written } \\
\text { language). }\end{array}$ \\
\hline & Readability & 46. Plain language and medical terms provided for the name of the procedure. \\
\hline & & $\begin{array}{l}\text { 47. Written at or below a 6th-8th grade reading level or written at a reading level that is compliant with the } \\
\text { state's recommended reading level for Medicaid patients. }\end{array}$ \\
\hline & Organisation & $\begin{array}{l}\text { 48. Use of: } \\
\text { a. Subheadings. } \\
\text { b. Checkboxes. } \\
\text { c. Bullet points. } \\
\text { 49. Diagrams, figures, graphs or pictures. }\end{array}$ \\
\hline & Length & 50. Limit on the number of pages. \\
\hline & & 51. Limit on the average time required for a patient to read/review the document. \\
\hline \multirow[t]{2}{*}{ Timing } & Time to review & $\begin{array}{l}\text { 52. Time stamp that indicates document received at least } 72 \text { hours (business days) prior to the procedure } \\
\text { date, unless patient opts out of review time in order to have the procedure sooner. }\end{array}$ \\
\hline & Consistency over time & $\begin{array}{l}\text { 53. Checkbox on consent document indicates consistency between document received prior to the } \\
\text { procedure and the document the patient signs. }\end{array}$ \\
\hline
\end{tabular}

We subsequently dropped 6 of the 15 items due to feasibility concerns, and combined a seventh item, plain language, into the item assessing written content in the document. Specifically, we found that it was not feasible to assess language preference or use of an interpreter, since this information is infrequently captured in the informed consent document or medical record. Postoperative expectations and inclusion of special clauses were also deemed not feasible to measure, as they may be provided to patients in other types of documents. We also decided not to assess the probability of procedurespecific benefits because these vary qualitatively and quantitatively by nuanced patient factors and are therefore more challenging to reliably assess. Finally, we did not include the item about anticipated anaesthesia mode as, alone, the information was felt to be inadequate and anesthesiologists often obtain distinct informed consent from patients. Arguably, with additional development and testing, future measures could include these and other items.

The final tool contained eight items and two subitems (table 3). Standards for abstracting these remaining items were developed over eight cycles, which was necessary to achieve $>90 \%$ item-level agreement between independent raters. Seven items related to the content of the procedure (name of the procedure, how it is performed, rationale for the procedure, quantitative probability of risk, qualitative probability of risk, description of benefits and description of alternatives) and one item assessed timing. Two subitems assessed presentation (whether the information was typewritten). Regarding timing, there was consensus among the working group that informed consent documents should be shared with patients at least 1 day before the procedure, unless the patient opts for same-day informed consent. Although the optimal timing may vary by person and procedure, and the original recommendation by the working group was that the document be shared at least 72 hours in advance of the procedure, such a provision would at least ensure that informed consent documents are not shared in the preoperative waiting area or, worse, after a dose of anaesthesia is given, and yet not inconvenience patients who prefer a more expedited process.

\section{Scoring approach}

We used feedback from the patient working group and the technical expert panel to develop a scoring rubric for the abstraction tool. Overall, both groups favoured weighting each item differently, rather than assigning equal credit for each item, as weighting allowed for greater value to be given to the items of greatest importance to patients. The timing item was considered to have the greatest potential impact on the quality of informed consent, and thus was given the most weight. Specifically, the members of the working group noted that when informed consent discussions occurred prior to the day of the procedure, they were richer and allowed more opportunities for participation, even if elements of that discussion were not described in the informed consent document. Since the document is typically signed during the informed consent discussion, focusing on the date of that signature provided an objective measure of when that discussion likely took place.

The 20-point scoring rubric for the eight items appears in table 3 . We assigned the items related to timing the greatest number of points (5) because the working group and technical expert panel considered this domain to be 
Table 3 Items included in the abstraction tool and suggested scoring approach

\begin{tabular}{|c|c|c|c|}
\hline Domain & Item & Response & Points \\
\hline & \multicolumn{3}{|l|}{ Description of procedure } \\
\hline \multirow[t]{2}{*}{ Content/presentation } & \multirow{2}{*}{$\begin{array}{l}\text { 1. Is language describing what the procedure is (beyond the } \\
\text { medical name) provided for the patient? (plain language) }\end{array}$} & 'Yes' & 2 \\
\hline & & ‘No' & 0 \\
\hline \multirow[t]{3}{*}{ Presentation } & \multirow[t]{3}{*}{ 1a. If provided, is it typed? } & 'Yes' & 1 \\
\hline & & 'No' & 0 \\
\hline & & 'N/A' & 0 \\
\hline \multirow[t]{2}{*}{ Content/presentation } & \multirow{2}{*}{$\begin{array}{l}\text { 2. Is a description of how the procedure will be performed } \\
\text { provided for the patient? (plain language) }\end{array}$} & 'Yes' & 2 \\
\hline & & ‘No' & 0 \\
\hline \multirow[t]{3}{*}{ Presentation } & \multirow[t]{3}{*}{ 2a. If provided, is it typed? } & 'Yes' & 1 \\
\hline & & 'No' & 0 \\
\hline & & 'N/A' & 0 \\
\hline
\end{tabular}

Rationale for procedure

\begin{tabular}{|c|c|c|c|}
\hline \multirow[t]{4}{*}{ Content } & \multirow[t]{3}{*}{$\begin{array}{l}\text { 3. Is the clinical rationale (condition-specific justification) for } \\
\text { why the procedure will be performed provided? }\end{array}$} & $\begin{array}{l}\text { 'Yes, context and condition given and fully } \\
\text { meet criteria' }\end{array}$ & 2 \\
\hline & & $\begin{array}{l}\text { 'Context and condition given, but do not } \\
\text { fully meet criteria' }\end{array}$ & 1 \\
\hline & & 'No, no rationale given' & 0 \\
\hline & \multicolumn{3}{|l|}{ Patient-oriented benefit(s) } \\
\hline \multirow[t]{2}{*}{ Content } & $\begin{array}{l}\text { 4. Is any patient-oriented benefit provided (intended impact } \\
\text { on the patient's health, longevity and/or quality of life)? }\end{array}$ & 'Yes' & 2 \\
\hline & \multicolumn{3}{|l|}{ Probability of procedure-specific risks } \\
\hline \multirow[t]{4}{*}{ Content } & \multirow{2}{*}{$\begin{array}{l}\text { 5. Is a quantitative probability provided for any procedure- } \\
\text { specific risk? }\end{array}$} & 'Yes' & 2 \\
\hline & & 'No' & 0 \\
\hline & \multirow{2}{*}{$\begin{array}{l}\text { 6. Is a qualitative probability provided for any procedure- } \\
\text { specific risk? }\end{array}$} & 'Yes' & 1 \\
\hline & & 'No' & 0 \\
\hline Content & Timing & & \\
\hline \multirow[t]{4}{*}{ Timing } & \multirow{3}{*}{$\begin{array}{l}\text { 8a. Date the document was shared with the patient; if not } \\
\text { available, the patient's/proxy's date of signature. } \\
8 \mathrm{~b} \text {. Date of procedure. } \\
8 \mathrm{c} \text {. Patient opted out of receiving the consent document at } \\
\text { least } 1 \text { day prior to the procedure. }\end{array}$} & $\begin{array}{l}\text { At least } 1 \text { day before procedure } O R \text { patient } \\
\text { opted out of viewing the informed consent } \\
\text { document at least } 1 \text { day prior. }\end{array}$ & 5 \\
\hline & & Less than 1 day before procedure. & 0 \\
\hline & & $\begin{array}{l}\text { Missing either date of patient's/proxy's } \\
\text { signature or missing date of procedure. }\end{array}$ & 0 \\
\hline & \multicolumn{2}{|l|}{ Maximum quality score } & 20 \\
\hline
\end{tabular}

For item 3, either 0,1 or 2 points are granted.

$\mathrm{N} / \mathrm{A}$, not applicable.

the most critical area for patient-centred decision making, and because these data could be easily abstracted and reliably measured. To rate this item, the date of the patient's or proxy's signature served as the date that the document was shared, although in the future, consent documents could note this separately.

\section{Item reliability for the abstraction tool}

Two raters independently reviewed 250 consent documents. The average time for reviewing each consent document was 3-4 min. Agreement reached $>90 \%$ for all items on the tool (table 4 ). Inter-rater reliability between items ranged from a Cohen's kappa statistic of 0.53 to 0.95. The high per cent agreement but low kappa for several of the items is a statistical phenomenon given the low prevalence of the positive answer. ${ }^{22}$

\section{Final abstraction tool}

Following iterative development and testing, the final tool comprised eight items. We counted legibility as part of two subitems. We did not require the other items to be typewritten given that the medical rationale, risks, benefits and alternatives should be individualised, and that not 
Table 4 Inter-rater reliability in the testing sample

\begin{tabular}{|c|c|c|}
\hline \multirow[b]{2}{*}{ Criterion/question on abstraction tool } & \multicolumn{2}{|c|}{$\begin{array}{l}\text { Agreement between two } \\
\text { raters }(n=250)\end{array}$} \\
\hline & $\%$ agreement & Kappa \\
\hline 1. Is language describing 'what is the procedure' (beyond the medical name) provided for the patient? & 92.0 & 0.81 \\
\hline 1a. If provided, is it typed? & 96.4 & 0.89 \\
\hline 2. Is a description of how the procedure will be performed provided for the patient? & 96.8 & 0.89 \\
\hline 2a. If provided, is it typed? & 98.0 & 0.92 \\
\hline $\begin{array}{l}\text { 4. Is any patient-oriented benefit provided (intended impact on the patient's health, longevity and/or quality of } \\
\text { life)? }\end{array}$ & 96.8 & 0.76 \\
\hline 5. Is a quantitative probability provided for any procedure-specific risk? & 97.6 & 0.61 \\
\hline 6. Is a qualitative probability provided for any procedure-specific risk? & 94.8 & 0.53 \\
\hline 7. Is any alternative provided for the patient? & 98.8 & 0.95 \\
\hline \multicolumn{3}{|l|}{ Document score agreement } \\
\hline Spearman correlation & 0.9164 & \\
\hline
\end{tabular}

NA, not applicable.

all health systems may be able to comply with a mandate for providing typewritten information.

\section{DISCUSSION}

We have developed, in collaboration with patients and patient advocates, clinicians, and experts in bioethics, law and medical decision making, an instrument for measuring the quality of informed consent documents for elective procedures. This work represents a step towards improving a critical component of clinical decision making that is necessary, although not sufficient, to support patient decision making. ${ }^{23}$ We adhered to the ethical and legal principles of informed consent while valuing consent that is obtained in a less transactional, less pro-forma process for patients. ${ }^{23}$ These principles and values are consistent with national goals for autonomous, patient-centred decision making from $\mathrm{CMS},{ }^{24-26}$ the Institute of Medicine, ${ }^{27}$ the Affordable Care Act's National Quality Strategy ${ }^{28}$ and the National Quality Forum's 'Safe Practices for Better Healthcare'. ${ }^{28}$ We then tested and confirmed the reliability of the tool. The result was a brief tool that can be used to develop a national measure of the quality of informed consent documents shared with patients.

CMS's Conditions for Participation require only written documentation that the elements of informed consent are discussed with the patient, ensuring that information imparted during the informed consent process aligns with communication between the patient and his or her clinician. ${ }^{18}$ In addition, no guidelines specify how much time patients must have to review informed consent information. In 2007, Washington State passed legislation incentivising clinicians to use a certified decision aid to facilitate shared decision making, instead of a traditional informed consent document and process, ${ }^{30}$ and thereby receive increased protection against litigation for failure to inform. However, this standard applies to only one state, is early in implementation, and does not pertain to circumstances where certified decision aids are not available. With more than 17.2 million elective procedures performed in hospital-owned ambulatory (58\%) and inpatient $(42 \%)$ settings each year, ${ }^{31}$ there is an urgent need to advance standards for informed consent that are more patient-centred. Our tool is intended to establish a minimum standard for the development and use of informed consent documents and, perhaps, advance efforts to implement certified decision aids and other elements of shared decision making.

Bringing attention to the content, presentation and timing of when informed consent documents are shared with patients is a novel concept, although well grounded in the evidence and bioethical standards of clinical practice. $^{32} 33$ Our abstraction tool assesses procedure-specific content such as how the procedure is performed, the clinical rationale for it and patient-oriented benefits (eg, relief of symptoms and years of life gained). Our tool also assesses whether an informed consent document identifies procedure-specific risks in both quantitative and qualitative terms, which was important to patients in the work group.

With respect to presentation, consent forms should be legible and readable to patients. The readability of informed consent documents has made little progress during the past 15 years and varies in the extent to which it aligns with informed consent guidelines. ${ }^{34} 35$ The Joint Commission suggests that health education materials be 
written at or below an eighth-grade reading level. ${ }^{36}$ Still, many consent forms are difficult for patients to read and comprehend, as they often require at least a high school reading level. ${ }^{34}$ In a study on the informed consent documents at 616 hospitals across the USA, the mean gradelevel readability score was $12.6( \pm 3.1)$ (above a 12th-grade reading level), substantially higher than the recommended eighth-grade level. ${ }^{34}$ In addition, an international study analysing the quality and readability of informed consent documents used in cardiology determined that the documents were written with poor quality and readability. ${ }^{37}$ One study found that lowering the reading level of consent forms for a clinical trial to a seventh-grade or eighth-grade reading level resulted in significantly lower consent-related anxiety and higher patient satisfaction. ${ }^{38}$

Similarly, using consent documents written in the patient's preferred language is essential to readability. Language barriers can prevent patient understanding, result in incomplete informed consent and consent documentation, ${ }^{39}$ and intensify healthcare disparities in racial and ethnic minorities. ${ }^{40}$ One study found that only $41 \%$ of Chinese-speaking and Spanish-speaking patients with limited English proficiency received informed consent documentation in their primary language or used an interpreter. $^{39}$

Our abstraction tool addresses some, but not all, of these concerns. One of our criteria is that essential information should be typed. In addition, the abstraction tool assesses whether information is conveyed in lay terms, not medical jargon. We did not, however, assess patient health literacy given that current assessment methods are fraught with inaccuracies and, without more integrative collection and measurement technology, are not likely to be feasible on a large scale. Additionally, our tool was only developed for documents written in English, as a first step. Further work is needed to develop tools to assess non-English informed consent documents.

Perhaps the most novel part of the tool is the item that assesses timing - that is, whether the informed consent document was shared one or more days before the elective procedure. In contrast to emergent procedures in which timing is not flexible, elective procedures are usually planned days, weeks and months in advance; still, patients are often asked to sign an informed consent document on the day of the elective procedure. Our prior study found that the majority of patients undergoing primary coronary revascularisation provided consent that same morning. ${ }^{10}$ Sharing important consent information just before an invasive procedure may not allow patients to sufficiently consider risks, benefits and alternatives; consult with family or friends; or seek a second medical opinion. Indeed, many patients first learn the details about a procedure and its alternatives during the informed consent discussion. ${ }^{241}$ Patients may also feel pressured to give consent because time is limited, because the clinician is physically present or because arrangements for the procedure have already been completed. ${ }^{6}$ In response, clinicians and patients supported assessing when the document is shared with the patient and requiring a reasonable amount of time for decision making to occur. We focused on the date the patient receives the document rather than the signature date, given that patients may want time to review the document's content and that returning a signed document before the procedure date may present logistical challenges. However, we recognise that most informed consent documents do not specify the date the document was shared, and in these cases the signature could be used as a proxy. Additionally, some stakeholders had concerns that stipulating at least a 1-day gap between the informed consent and the day of the procedure could lead to inconvenience and unnecessary delays. To address this, we included criteria that the patient could opt out of viewing/signing the informed consent at least 1 day prior; if documented as such, the scoring card would give credit for timing.

Overall, by identifying specific criteria for the content, presentation and timing of delivery of informed consent documents, our abstraction tool gives hospitals, health systems and clinicians the guidance to improve their existing documents in the absence of precise state or federal standards. The tool also has the potential to illuminate hospital-level or health-system variation, as well as group-practice or clinician-level variation, in the quality of informed consent documents. It also may increase the level of attention and resources that providers dedicate to creating high-quality informed consent documents and processes.

Our approach to developing this tool has several limitations. First, our informed consent taxonomy is merely intended to be a working document, capturing the informational needs of patients (as demonstrated in prior literature), our interactions with patients and advocacy groups, and broader societal trends. The quality domains do not represent all elements that are important to all people; as providers work to meet the standards put forth in this tool, new expectations may emerge, leading to potential modifications to the tool. Additionally, these quality domains (and their execution in the informed consent documentation) may need to be adapted or expanded for low-literacy populations. Second, our abstraction tool establishes only a minimum standard for informed consent documents, not a definitive benchmark of achievement. The major critique by our patient and patient advocate team members was that a focus on minimum documentation standards would not necessarily improve the entire informed consent process. However, they agreed that an adequate document is a minimum requirement of informed consent. This abstraction tool is a first step towards improving the practice of obtaining informed consent. In developing this tool, we offer a concrete way to improve procedurerelated information exchange to support informed decision making by patients and providers. With input from patients, clinicians and health systems, the tool can be expanded in the future to capture other key elements of informed consent quality that may further support 
decision making, such as patient-reported experiences. Ultimately, the explicit sharing of information about the risks, benefits and alternatives can build transparency and help to facilitate a more expansive framework of autonomy that acknowledges individuality while recognising the social and relational context that guides a more shared decision-making process. ${ }^{42}$ Third, the evaluation of informed consent quality standards is somewhat subjective. To mitigate variability in interpretation of quality, we developed definitions, rules and examples to guide reliable abstraction across raters and confirmed the tool's reliability across multiple procedures, hospitals and raters. Fourth, this tool was intended to evaluate informed consent for elective procedures; tools designed to assess informed consent documents associated with emergently performed procedures may prioritise different standards. Fifth, while this tool only captures some quality items from the taxonomy, there is no external standard with which to compare. That is, some excluded items may be necessary to support a high-quality document; on the other hand, not all elements captured in the tool may be necessary to support quality. For example, if a patient prefers to sign the informed consent document on the day of the procedure as opposed to at least 1 day prior, then the timing item may not reflect quality. To account for this, we added an option for patients to decline reviewing the information 1 day prior, although this may not be documented and thus credit would be lost. Still, the scoring system does count a timely consent form which fails all other criteria as higher quality than one which meets all other criteria but is not timely; while this reflects the consensus values of our stakehold input, it may not reflect every patient's values. Ultimately, the definition of quality may change depending on the goal. Since the goal for this project was to generate a nationally applicable tool that could be used by hospitals and providers to assay quality, we attempted to define a minimum standard that advances the status quo, although may not achieve a benchmark for quality.

\section{CONCLUSION}

We developed a comprehensive taxonomy of the elements of high-quality informed consent documents with patients and patient advocates. Based on this, we constructed a brief instrument for evaluating the quality of informed consent documents. The items in the tool are in alignment with bioethical principles, state laws and hospital policies. The tool is easy to use and can illuminate deficiencies in the quality of informed consent documents. Such illumination could encourage providers to improve their informed consent documents, thereby better equipping patients to make autonomous decisions about planned elective procedures. In addition, the information obtained from applying this tool can be used to develop a measure of informed consent document quality to further improve decision making between patients and clinicians by holding them to a minimum standard.

\section{Author affiliations}

${ }^{1}$ Section of Cardiovascular Medicine, Yale School of Medicine, New Haven, Connecticut, USA

${ }^{2}$ Yale-New Haven Health Center for Outcomes Research and Evaluation, Yale School of Medicine, New Haven, Connecticut, USA

${ }^{3}$ Section of Rheumatology, Yale School of Medicine, New Haven, Connecticut, USA

${ }^{4}$ School of Medicine, Quinnipiac University, Hamden, Connecticut, USA

${ }^{5}$ Dartmouth College Geisel School of Medicine, Hanover, New Hampshire, USA

${ }^{6}$ Robert Wood Johnson Foundation Clinical Scholars Program, Yale School of

Medicine, New Haven, Connecticut, USA

${ }^{7}$ Health Policy and Administration, Yale School of Public Health, New Haven, Connecticut, USA

${ }^{8}$ Obstetrics and Gynecology, Yale School of Medicine, New Haven, Connecticut, USA ${ }^{9}$ Section of General Internal Medicine, Yale School of Medicine, New Haven, CT, USA

\section{Twitter Erica S Spatz @SpatzErica and Harlan M Krumholz @hmkyale}

Acknowledgements The authors thank the working group for their time and commitment to this effort. They include Ellen Andrews, Irwin Birnbaum, Larry Bocchiere III, Jonathan Delman, Gaye Hyre, Marilyn Mann, Chris Norton, Patricia Skolnik and Amos Smith. The authors would also like to thank the members of the technical expert panel for their input on the instrument. Finally, they would like to thank Steven DeMaio for his contributions to the early drafting of the manuscript.

Contributors All authors substantially contributed to the manuscript. ES: conceptual design, interpretation of data, drafting of the manuscript. LS, LC, ZL, SMB, HMK: conceptual design, interpretation of data, critical revisions to the manuscript. EG, MP: conceptual design, data collection, interpretation of data, critical revisions to the manuscript. VD: data collection, interpretation of data, critical revisions to the manuscript. $\mathrm{HB}$, JH: data analysis, interpretation of data, critical revisions to the manuscript. LLG: conceptual design, critical revisions to the manuscript.

Funding The data collection and analyses on which this publication is based were performed under the Measure and Instrument Development and Support (MIDS) contract HHSM-500-2013-13018l, Task Order HHSM-500-T0001-Development, Reevaluation, and Implementation of Outcome/Efficiency Measures for Hospital and Eligible Clinicians, Option Year 3, funded by the Centers for Medicare and Medicaid Services, an agency of the US Department of Health and Human Services. The funder had no role in the design, preparation and conduct of the study; and in the collection, management, analysis and interpretation of the data; however, the funder was involved in the review and approval of the manuscript and decision to submit the manuscript for publication. The content of this publication does not necessarily reflect the views or policies of the Department of Health and Human Services nor does the mention of trade names, commercial products or organisations imply endorsement by the US government. The authors assume full responsibility for the accuracy and completeness of the ideas presented. At the time of this study, ES was supported by grant K12HS023000 from the Agency for Healthcare Research and Quality Patient-Centered Outcomes Research Institute (PCORI) Mentored Career Development Program.

Competing interests The authors of this manuscript receive support to develop quality measures for the Centers for Medicare and Medicaid Services for public reporting. The informed consent measure is not currently implemented but was made publicly available so that hospitals could use the measure as a selfevaluation tool. The authors report working under contract with the Centers for Medicare and Medicaid Services to support quality measurement programmes, including developing a measure of informed consent document quality. The measure is not currently part of any quality reporting programmes, although the Centers for Medicare and Medicaid Services has made publicly available for use by hospitals to support quality improvement efforts. ES also reports receiving support from the Food and Drug Administration to support projects within the Yale-Mayo Clinic Center of Excellence in Regulatory Science and Innovation (CERSI); from the National Institute on Minority Health and Health Disparities (U54MD010711-01) to study precision-based approaches to diagnosing and preventing hypertension; and from the National Institute of Biomedical Imaging and Bioengineering (R01 EB028106-01) to study a cuff-less blood pressure device. HMK also reports being a recipient of a research grant, through Yale, from Medtronic and the US Food and Drug Administration to develop methods for postmarket surveillance of medical devices; was a recipient of a research grant with Medtronic and is the recipient of a research grant from Johnson \& Johnson, through Yale University, to support clinical trial data sharing; was a recipient of a research agreement, through Yale University, from the Shenzhen Center for Health Information for work to advance intelligent 
disease prevention and health promotion; collaborates with the National Center for Cardiovascular Diseases in Beijing; receives payment from the Arnold \& Porter Law Firm for work related to the Sanofi clopidogrel litigation, from the Ben C Martin Law Firm for work related to the Cook Celect IVC filter litigation, and from the Siegfried and Jensen Law Firm for work related to Vioxx litigation; chairs a Cardiac Scientific Advisory Board for UnitedHealth; was a participant/participant representative of the IBM Watson Health Life Sciences Board; is a member of the Advisory Board for Element Science, the Advisory Board for Facebook and the Physician Advisory Board for Aetna; and is the cofounder of Hugo Health, a personal health information platform, and cofounder of Refactor Health, an enterprise healthcare Al-augmented data management company.

Patient and public involvement Patients and/or the public were involved in the design, or conduct, or reporting, or dissemination plans of this research. Refer to the Methods section for further details.

\section{Patient consent for publication Not required.}

Ethics approval The institutional review boards of Yale University and of HSAG and Premier approved the study.

Provenance and peer review Not commissioned; externally peer reviewed.

Data availability statement Data are available upon reasonable request. The iterative versions of the abstraction tool can be made available upon request. The informed consent documents used to develop and test the abstraction tool cannot be shared given the confidential patient and provider information, and data use agreements with CMS and partnering hospitals.

Open access This is an open access article distributed in accordance with the Creative Commons Attribution Non Commercial (CC BY-NC 4.0) license, which permits others to distribute, remix, adapt, build upon this work non-commercially, and license their derivative works on different terms, provided the original work is properly cited, appropriate credit is given, any changes made indicated, and the use is non-commercial. See: http://creativecommons.org/licenses/by-nc/4.0/.

\section{ORCID iDs}

Erica S Spatz http://orcid.org/0000-0002-1557-7713

Leslie Curry http://orcid.org/0000-0002-3419-4654

Harlan M Krumholz http://orcid.org/0000-0003-2046-127X

\section{REFERENCES}

1 Centers for Disease Control and Prevention (U.S.), Office of the Associate Director for Communication, Strategic and Proactive Communication Branch. Simply put; a guide for creating easy-tounderstand materials, 2010. Available: http://stacks.cdc.gov/view/ cdc/11938 [Accessed 5 Jul 2016].

2 Krumholz HM. Informed consent to promote patient-centered care. JAMA 2010;303:1190-1.

3 Spatz ES, Krumholz HM, Moulton BW. The new era of informed consent: getting to a Reasonable-Patient standard through shared decision making. JAMA 2016;315:2063-4.

4 Bottrell MM, Alpert H, Fischbach RL, et al. Hospital informed consent for procedure forms: facilitating quality patient-physician interaction. Arch Surg 2000;135:26-33.

5 Faden R, Beauchamp T. A history and theory of informed consent. New York: Oxford University Press, 1986.

6 Habiba M, Jackson C, Akkad A, et al. Women's accounts of consenting to surgery: is consent a quality problem? Qual Saf Health Care 2004;13:422-7.

7 Dixon-Woods M, Williams SJ, Jackson CJ, et al. Why do women consent to surgery, even when they do not want to? an interactionist and Bourdieusian analysis. Soc Sci Med 2006;62:2742-53.

8 Grundner TM. On the readability of surgical consent forms. N Engl J Med 1980;302:900-2.

9 Braddock $\mathrm{CH}$, Edwards KA, Hasenberg NM, et al. Informed decision making in outpatient practice: time to get back to basics. JAMA 1999;282:2313-20.

10 Shahu A, Schwartz J, Perez M, et al. Discerning quality: an analysis of informed consent documents for common cardiovascular procedures. BMJ Qual Saf 2017;26:569-71.

11 Grady C. Enduring and emerging challenges of informed consent. $N$ Engl J Med 2015;372:855-62.

12 Spertus JA, Bach R, Bethea C, et al. Improving the process of informed consent for percutaneous coronary intervention: patient outcomes from the patient risk information services manager (ePRISM) study. Am Heart J 2015;169:234-41.
13 Schenker Y, Fernandez A, Sudore R, et al. Interventions to improve patient comprehension in informed consent for medical and surgical procedures: a systematic review. Med Decis Making 2011;31:151-73.

14 Arnold SV, Decker C, Ahmad H, et al. Converting the informed consent from a perfunctory process to an evidence-based foundation for patient decision making. Circ Cardiovasc Qual Outcomes 2008;1:21-8.

15 Scholl I, Loon MK-van, Sepucha K, et al. Measurement of shared decision making - a review of instruments. Zeitschrift für Evidenz, Fortbildung und Qualität im Gesundheitswesen 2011;105:313-24.

16 Electronic Code of Federal Regulations. Part 482-Conditions of participation for hospitals, §482.24, §482.51, §482.90, §482.98, \$482.102.. Available: http://www.ecfr.gov/cgi-bin/text-idx?SID=faac $625 \mathrm{~d} 3284209 \mathrm{cb} 805 \mathrm{fb} 0 \mathrm{~b} 44 \mathrm{c} 941 \mathrm{fa} \& \mathrm{mc}=$ true\&node $=$ pt42.5.482\&rgn= div5\#se42.5.482 124

17 Spatz ES, Bao H, Herrin J. Quality of informed consent documentsamong us. hospitals: a crosssectional study. BMJ Open 2020;0:e033299.

18 Department of Health \& Human Services, Centers for Medicare \& Medicaid Services (CMS). CMS Manual System. Regulations and Interpretive Guidelines for Hospitals - Condition of Participation: Medical Record Services. Sections 482.13(b), 482.24(b), 482.51(b)(2, 2008. https://www.cms.gov/Regulations-and-Guidance/Guidance/ Transmittals/downloads/R37SOMA.pdf

19 The Joint Commission. Requirements related to the provision of culturally competent patient-centered care hospital accreditation program (HAP): informed consent (standards RI.01.02.01,

RI.01.03.01). 2009, 2009. Available: http://www.jointcommission.org/ assets/1/6/2009_CLASRelatedStandardsHAP.pdf [Accessed 5 Jul 2016].

20 The Joint Commission. Quick safety: an Advisory on safety and quality issues. Informed consent more than getting a signature, 2016. Available: https://www.jointcommission.org/assets/1/23/Quick Safety_Issue_Twenty-One_February_2016.pdf [Accessed 5 Jul 2016]

21 Horowitz LIG, Dorsey, KB JN. Measure Updates and Specifications Reports: Hospital-Wide All-Cause Unplanned Readmission - Version 3.0, 2014. Available: https://www.qualitynet.org/dcs/ContentServer? cid=1228774371008\&pagename=QnetPublic\%2FPage\% 2FQnetTier4\&c=Page [Accessed 15 Sep 2016]

22 Feinstein AR, Cicchetti DV. High agreement but low kappa: I. The problems of two paradoxes. J Clin Epidemiol 1990;43:543-9.

23 Beauchamp TL. Autonomy and consent. In: Miller FG, Wertheimer A, eds. The ethics of consent. New York: Oxford University Press, 2010

24 Centers for Medicare \& Medicaid Services. Beneficiary engagement and incentives models: shared decision making model. Innovation models: Centers for Medicare and Medicaid Services, 2016.

25 Centers for Medicare \& Medicaid Services. Decision MEMO for screening for lung cancer with low dose computed tomography (LDCT) (CAG-00439N), 2015. Available: https://www.cms.gov/ medicare-coverage-database/details/nca-decision-memo.aspx? NCAld=274 [Accessed 5 Jul 2016].

26 Centers for Medicare, Medicaid Services (CMS). Decision MEMO for percutaneous left atrial appendage (LAA) closure therapy (CAG00445N)., 2016. Available: https://www.cms.gov/medicare-coveragedatabase/details/nca-decision-memo.aspx?NCAld=281 [Accessed 5 Mar 2017].

27 Sugarman J. Informed consent: why do we care? Institute of medicine (IOM). informed consent and health literacy: a workshop. Washington, D.C: National Academy Press, 2014. http://www. nationalacademies.org/hmd/ /media/Files/Activity\%20Files/ PublicHealth/HealthLiteracy/2014-JUL-28/Sugarman.pdf

28 National Quality Forum (NQF). Safe practices for better Healthcare2010 update. A consensus report. Washington, DC: NQF, 2010. Available: http://www.qualityforum.org/publications/2010/04/safe practices_for_better_healthcare_\%E2\%80\%93_2010_update.aspx [Accessed 5 July 2016].

29 Department of Health and Human Services. Centers for Medicare and Medicaid Services (CMS). CMS Quality Strategy, 2016. Available: https://www.cms.gov/Medicare/Quality-Initiatives-PatientAssessment-Instruments/QualitylnitiativesGenlnfo/Downloads/CMSQuality-Strategy.pdf [Accessed 5 July 2016].

30 Washington State Legislature. Consent Form-Contents-Prima Facie Evidence-Shared decision Making-Patient decision Aid-Failure to use. title 7, chapter 770, section 770060 . Washington state legislature. Available: http://app.leg.wa.gov/rcw/default.aspx?cite=7. 70.060 [Accessed 16 Sep 2016].

31 Agency for Healthcare Research and Quality. Surgeries in HospitalBased Ambulatory Surgery and Hospital Inapatient Settings, 2014. Statistical Brief \#223. Healthcare Cost and Utilization Project, 2017.

32 Kinnersley P, Phillips K, Savage K, et al. Interventions to promote informed consent for patients undergoing surgical and other 
invasive healthcare procedures. Cochrane Database Syst Rev 2013;40:Cd009445.

33 Stacey D, Legare F, Col NF, et al. Decision AIDS for people facing health treatment or screening decisions. The Cochrane database of systematic reviews 2014;1:Cd001431.

34 Hopper KD, TenHave TR, Tully DA, et al. The readability of currently used surgical/procedure consent forms in the United States. Surgery 1998;123:496-503.

35 Cordasco KM. Obtaining Informed Consent From Patients: Brief Update Review. In: Making health care safer II: an updated critical analysis of the evidence for patient safety Practicespractices. (evidence Reports/Technology assessments, no. 211. Rockville (MD): Agency for Healthcare Research and Quality (US), 2013. http://www. ncbi.nlm.nih.gov/books/NBK133402/

36 The Joint Commission. "What Did the Doctor Say?:" Improving Health Literacy to Protect Patient Safety, 2007.
37 Terranova G, Ferro M, Carpeggiani C, et al. Low quality and lack of clarity of current informed consent forms in cardiology: how to improve them. JACC Cardiovasc Imaging 2012;5:649-55.

38 Coyne CA, Xu R, Raich P, et al. Randomized, controlled trial of an easy-to-read informed consent statement for clinical trial participation: a study of the eastern cooperative Oncology Group. $J$ Clin Oncol 2003;21:836-42.

39 Schenker Y, Wang F, Selig SJ, et al. The impact of language barriers on documentation of informed consent at a hospital with on-site interpreter services. J Gen Intern Med 2007;22 Suppl 2:294-9.

40 Nielsen-Bohlman L, Panzer AM, Kindig DA, Institute of Medicine (US), Committee on Health Literacy. A prescription to end confusion. Washington DC: National Academies Press (US), 2004.

41 Anderson OA, Wearne IMJ. Informed consent for elective surgery-what is best practice? J R Soc Med 2007;100:97-100.

42 Dove ES, Kelly SE, Lucivero F, et al. Beyond individualism: is there a place for relational autonomy in clinical practice and research? Clin Ethics 2017;12:150-65. 